\title{
A SEGUNDA CONFERÊNCIA DAS NAÇÕES UNIDAS SOBRE ASSENTAMENTOS HUMANOS: DOS PREPARATIVOS ÀS ALTERAÇÕES NA LEGISLAÇÃO BRASILEIRA - PARTE I
}

\section{THE SECOND UNITED NATIONS CONFERENCE ON HUMAN SETTLEMENTS: FROM PREPARATIONS TO CHANGES IN BRAZILIAN LEGISLATION - PART I}

\section{Josué Mastrodi ${ }^{1}$ \\ Beatriz Duarte Correa de Brito²}

\section{RESUMO}

Esse artigo tem por objetivo explicar o que foi a Segunda Conferência das Nações Unidas sobre Assentamentos Humanos (Habitat II), realizada em 1996, em Istambul, na Turquia, bem como os seus desdobramentos na legislação brasileira pós-1996. Após uma breve exposição a respeito do déficit habitacional brasileiro atual, foi analisado o contexto histórico em que a Habitat II esteve inserida, bem como os eventos preparatórios à Conferência. Posteriormente, foi estudada a Declaração de Istambul (seu documento final), que focou na sustentabilidade social, ambiental e econômica dos assentamentos humanos para conceituar moradia adequada. A partir desse estudo, foi possível analisar, na Parte II deste trabalho, os reflexos dessa Conferência na legislação federal brasileira sobre direito à moradia.

Palavras-chave: Direito à Moradia. Direito à Cidade. Conferências ONU. Habitat II. Sustentabilidade.

\section{ABSTRACT}

This article aims to explain the Second United Nations Conference on Human Settlements (Habitat II), held in Istanbul, Turkey, in 1996, as well as its developments in Brazilian legislation post-1996. After a brief presentation on the current Brazilian housing deficit, we analyzed the historical context in which Habitat II was inserted, as well as the preparatory events for the Conference. Subsequently, the Istanbul Declaration (its final document) was studied, which focused on the social, environmental and economic

\footnotetext{
${ }^{1}$ Doutor em Filosofia e Teoria Geral do Direito pela Universidade de São Paulo (2008). Mestre em Direito da Administração Pública pela Universidade Gama Filho (2003). Especialista em Direito Empresarial pela Pontifícia Universidade Católica de São Paulo (1999). Bacharel em Direito pela Universidade de São Paulo (1994). Professor Titular Categoria A2 da Pontifícia Universidade Católica de Campinas. Membro do corpo docente permanente dos Programas de Pós-Graduação stricto sensu em Direito (PPGD) e em Sustentabilidade (PPGS) da PUC-Campinas. Orientador de mestrado. Líder do grupo de pesquisa 'Direito e Realidade Social' (CNPq/PUC-Campinas). Afiliação: Pontifícia Universidade Católica de Campinas. Lattes: http://lattes.cnpq.br/6635472231072927 ORCID: https://orcid.org/0000-0003-4834-0170 E-mail: mastrodi@gmail.com

2 Mestra em Sustentabilidade pela Pontifícia Universidade Católica de Campinas. Possui graduação em Direito pela Pontifícia Universidade Católica de Campinas. Tem experiência na área de Direito, com ênfase em Direito Público. Possui curso-técnico-profissionalizante em Meio Ambiente pelo Colégio Técnico de Campinas - Unicamp. Afiliação: Pontifícia Universidade Católica de Campinas. Lattes: http://lattes.cnpq.br/1762052051033179. ORCID: https://orcid.org/0000-0001-6638-3700 E-mail: beatriz.brito@mail.com
} 
sustainability of human settlements to conceptualize adequate housing. From this study, it was possible to analyze, in Part II of this work, the reflections of this Conference on Brazilian federal legislation regarding the right to housing.

Keywords: Right to Housing. Right to the City. Conferences UN. Habitat II. Sustainability.

\section{INTRODUÇÃO}

O direito à moradia é um direito social, incluído no ano 2000 pela Emenda Constitucional (EC) n. 26 no artigo 60 da Constituição Federal (CF); um direito humano, presente em tratados internacionais, como no artigo 25, §1으 da Declaração Universal dos Direitos Humanos (DUDH); um direito absoluto, segundo urbanistas como Ermínia Maricato (2017). Um direito com muitos títulos, porém pouco respeitado no Brasil.

Tratado inicialmente apenas como um direito a ter um local para viver, o direito à moradia desponta no cenário internacional desde meados do século passado, quando foi proclamada, em dezembro de 1948, pela Assembleia Geral da Organização das Nações Unidas (ONU), a Declaração Universal dos Direitos Humanos (DUDH), que, ao reconhecer que "a dignidade inerente a todos os membros da família humana e de seus direitos iguais e inalienáveis é o fundamento da liberdade, da justiça e da paz no mundo" (FIORILLO, 2017, p. 194), prescreveu em seu artigo 25, §1으, que:

Toda pessoa tem direito a um padrão de vida capaz de assegurar a si e a sua família saúde e bem-estar, inclusive alimentação, vestuário, habitação, cuidados médicos e os serviços sociais indispensáveis, e direito à segurança em caso de desemprego, doença, invalidez, viuvez, velhice ou outros casos de perda dos meios de subsistência em circunstâncias fora de seu controle. (ONU, 1948) - grifo nosso

Esse direito foi reforçado pelo Pacto Internacional sobre os Direitos Econômicos, Sociais e Culturais (PIDESC), assinado em 1966 no âmbito da ONU e ratificado pelo Brasil somente em 1992. Dispõe o Artigo 11.1 desse Pacto:

Os Estados-Partes no presente Pacto reconhecem o direito de todas as pessoas a um nível de vida suficiente para si e para as suas famílias, incluindo alimentação, vestuário e alojamento suficientes, bem como a um melhoramento constante das suas condições de existência. Os Estados Partes tomarão medidas apropriadas destinadas a assegurar a realização deste direito reconhecendo para este efeito a importância essencial de uma cooperação internacional livremente consentida. (ONU, 1966) - grifo nosso

Visando a explicar melhor cada um dos itens desse pacto, o Comitê dos Direitos Econômicos, Sociais e Culturais (CDESC) divulga, desde 1989, "sua interpretação sobre o conteúdo dos padrões de 
direitos humanos na forma de Comentários Gerais sobre temas específicos" (ONU, 2017). Em 1991, durante a Sexta Sessão, o CDESC publicou o Comentário Geral n. 4 (CG4), referente ao artigo 11 do PIDESC, no qual, além de traçar a situação mundial da habitação e definir conceitos importantes, estabeleceu os requisitos para uma moradia ${ }^{3}$ ser considerada adequada. São eles: segurança legal da ocupação; disponibilidade de serviços, materiais, equipamentos e infraestruturas; acessibilidade; habitabilidade; facilidade de acesso; localização; respeito pelo meio cultural (CDESC, 1991).

Em 1997, o CDESC publicou o Comentário Geral n. 7 (CG7), também em relação ao artigo 11 do PIDESC, criticando as remoções forçadas, claramente ofensivas aos direitos humanos. O Comitê ressaltou que as utilizações desse instrumento como "medidas punitivas são inconsistentes com as normas do Pacto" (CDESC, 1997) e que é dever da autoridade responsável "assegurar que essas remoções forçadas sejam realizadas de acordo com a lei" (CDESC, 1997).

Importante ressaltar que o PIDESC é um Tratado Internacional de Direitos Humanos e, assim como os demais tratados internacionais, para ter validade jurídica no ordenamento jurídico de um país, deve ser ratificado e internalizado. No caso do Brasil, após as discussões e assinatura do tratado pelo presidente da República ${ }^{4}$, cabe ao Congresso Nacional ${ }^{5}$ aprová-lo, ocorrendo, assim, o depósito da ratificação, em âmbito internacional. Posteriormente, em âmbito nacional, o documento é promulgado por meio de decreto presidencial, quando, então, começa a ter validade no ordenamento jurídico brasileiro.

Como são documentos internacionais internalizados por meio de decreto presidencial, a discussão sobre sua hierarquia em relação às demais leis sempre permeou o mundo jurídico, até a EC n. 45 de 2004 estabelecer uma regra definidora de hierarquia entre normas, ao incluir no artigo 5o da CF o parágrafo 3 ㅇ:

Os tratados e convenções internacionais sobre direitos humanos que forem aprovados, em cada Casa do Congresso Nacional, em dois turnos, por três quintos dos votos dos respectivos membros, serão equivalentes às emendas constitucionais (BRASIL, 1988).

Segundo o entendimento histórico do Supremo Tribunal Federal (STF), os tratados internacionais internalizados tinham status legal, ou seja, eram inferiores à CF e se igualavam às leis federais. Todavia, com o advento da EC n. 45 de 2004, a Suprema Corte mudou o entendimento, e, a partir de 2008, passou a considerar que os tratados internacionais de direitos humanos incorporados antes da EC n. 45 de 2004 tinham status supralegal, ou seja, eram hierarquicamente superiores às leis ordinárias (conforme

\footnotetext{
${ }^{3}$ Apesar das definições doutrinárias que apresentam distinção entre os conceitos de moradia e habitação, nesse trabalho os termos foram utilizados como sinônimos.

${ }^{4}$ Nos termos do artigo 84 , VIII, da Constituição Federal.

${ }^{5}$ Nos termos do artigo 49, I, da Constituição Federal.
} 
pretendia o novo ordenamento jurídico), todavia inferiores à CF (entendimento histórico do STF) (RAMANZINI, 2014).

Em seu voto no Recurso Extraordinário n. 466.343-1/SP, o Ministro Gilmar Mendes explica o entendimento da Suprema Corte, a partir de então, em relação à incorporação dos tratados internacionais ao ordenamento jurídico nacional. O Ministro destaca em seu voto que a Corte entendia que os tratados internacionais eram equiparados à legislação ordinária:

Sob a égide da Constituição de 1988, exatamente em 22 de novembro de 1995, o Plenário do STF voltou a discutir a matéria no HC n. 72.131/RJ, Red. p/ o acórdão Ministro Moreira Alves, porém agora tendo como foco o problema específico da prisão civil do devedor como depositário infiel na alienação fiduciária em garantia. $\mathrm{Na}$ ocasião, reafirmou-se o entendimento de que os diplomas normativos de caráter internacional adentram o ordenamento jurídico interno no patamar da legislação ordinária e eventuais conflitos normativos resolvem-se pela regra lex posterior derrogat legi priori (MENDES, 2008, p. 13).

O Ministro afirmou que a "a discussão em torno do status constitucional dos tratados de direitos humanos foi, de certa forma, esvaziada pela promulgação da Emenda Constitucional n. 45/2004, a Reforma do Judiciário" (MENDES, 2008, p. 10) e que tal reforma "acabou por ressaltar o caráter especial dos tratados de direitos humanos em relação aos demais tratados de reciprocidade entre os Estados pactuantes, conferindo-Ihes lugar privilegiado no ordenamento jurídico" (MENDES, 2008, p. 11).

E essa nova ordem constitucional deveria resultar em um novo entendimento do STF sobre o tema:

A mudança constitucional ao menos acena para a insuficiência da tese da legalidade ordinária dos tratados e convenções internacionais já ratificados pelo Brasil, a qual tem sido preconizada pela jurisprudência do Supremo Tribunal Federal desde o remoto julgamento do RE $n^{\circ} 80.004 /$ SE (MENDES, 2008, p. 11).

$[\ldots]$

Tudo indica, portanto, que a jurisprudência do Supremo Tribunal Federal, sem sombra de dúvidas, tem de ser revisitada criticamente (MENDES, 2008, p. 19).

E explicou que essa mudança se fez necessária em razão da existência de um novo Estado Constitucional: o “Estado Constitucional Cooperativo", que se integra aos demais Estados Constitucionais da comunidade internacional. Nessa nova ordem constitucional, segundo Mendes, os direitos humanos e fundamentais têm maior relevância, sendo sua proteção o "corolário da própria garantia da dignidade da pessoa humana" (MENDES, 2008, p. 15).

Gilmar Mendes afirmou, então, que a própria CF sinaliza para uma abertura do direito nacional para o direito internacional, com uma maior integração com os organismos internacionais. Esses sinais, segundo ele, podem ser encontrados no artigo 4으, parágrafo único, e no artigo 5으, §§2으, 3으 e 4으, todos da 
CF. Ele ressalta ainda, que há uma "tendência contemporânea do constitucionalismo mundial de prestigiar as normas internacionais destinadas à proteção do ser humano" (MENDES, 2008, p. 18).

O Ministro, então, passou a explicar o novo entendimento da Corte sobre o assunto, entendimento esse que passou a ser adotado a partir desse julgamento:

A tese da legalidade ordinária, na medida em que permite ao Estado brasileiro, ao fim e ao cabo, o descumprimento unilateral de um acordo internacional, vai de encontro aos princípios internacionais fixados pela Convenção de Viena sobre o Direito dos Tratados, de 1969, a qual, em seu art. 27, determina que nenhum Estado pactuante "pode invocar as disposições de seu direito interno para justificar o inadimplemento de um tratado".

Por conseguinte, parece mais consistente a interpretação que atribui a característica de supralegalidade aos tratados e convenções de direitos humanos. Essa tese pugna pelo argumento de que os tratados sobre direitos humanos seriam infraconstitucionais, porém, diante de seu caráter especial em relação aos demais atos normativos internacionais, também seriam dotados de um atributo de supralegalidade.

Em outros termos, os tratados sobre direitos humanos não poderiam afrontar a supremacia da Constituição, mas teriam lugar especial reservado no ordenamento jurídico. Equipará-los à legislação ordinária seria subestimar o seu valor especial no contexto do sistema de proteção dos direitos da pessoa humana.

\section{$[\ldots]$}

Assim, a premente necessidade de se dar efetividade à proteção dos direitos humanos nos planos interno e internacional torna imperiosa uma mudança de posição quanto ao papel dos tratados internacionais sobre direitos na ordem jurídica nacional.

É necessário assumir uma postura jurisdicional mais adequada às realidades emergentes em âmbitos supranacionais, voltadas primordialmente à proteção do ser humano (MENDES, 2008, p.19).

Mendes, por fim, resumiu esse novo entendimento, afirmando que a legislação conflitante com o disposto em tratados internacionais de direitos humanos dos quais o Brasil é signatário deve ter sua eficácia jurídica suspensa (MENDES, 2008).

Dessa forma, o PIDESC, promulgado pelo Decreto presidencial n. 592, de 06 de julho de 1992, é uma norma supralegal, o que significa que, em eventual conflito com leis ordinárias e complementares, pelo critério da hierarquia, o primeiro prevalece. Todavia, o mesmo não ocorre em relação à CF, norma hierarquicamente superior a todas as outras.

Já a DUDH não pode ser internalizada, visto que não se trata de um tratado internacional, mas tão somente de "uma recomendação de maior solenidade, utilizada em raras ocasiões relacionadas a matérias de grande importância, em que se espera o máximo comprometimento moral e político dos partícipes" (ARZABE, GRACIANO, 2017, p.1). Ou seja, é um documento internacional que orienta os países no respeito aos direitos humanos, todavia, de forma não vinculante.

Feita essa ressalva, retornemos ao direito à moradia, que somente ganhou destaque no plano internacional da década de 1970 (MAUAD, 2011), quando ocorreu em Vancouver, Canadá, a Primeira 
Conferência das Nações Unidas sobre Assentamentos Humanos, conhecida como Habitat I. A partir de então, moradia deixou de ser entendida somente como a estrutura onde as pessoas vivem, e passou a ser tratada como "um sistema integral que compreende também o terreno, a infraestrutura para urbanização e serviços e o equipamento social e comunitário, dentro de um contexto cultural, socioeconômico, político e físico-ambiental" (ONU, 1976).

Com o advento da Declaração sobre Assentamentos Humanos de Vancouver, resultado da Habitat I, as mudanças em relação ao direito à moradia começaram. Porém, as mudanças foram tímidas em razão da quase que exclusiva preocupação dos países e organismos internacionais com a disputa políticoideológica predominante na Guerra Fria, que concentrava a atuação destes no alinhamento com uma das duas potências, deixando a preocupação com os direitos sociais em segundo plano (MAUAD, 2011).

Já na década de 1990, com o fim da Guerra Fria, os temas sociais ganharam força na agenda internacional, ocupando os espaços antes dedicados a assuntos de segurança e desarmamento (RUBARTH, 1990), culminando em diversas Conferências da ONU, dentre elas a Conferência das Nações Unidas sobre o Meio Ambiente e o Desenvolvimento (Rio-92), em 1992, no Rio de Janeiro, Brasil, e a Segunda Conferência das Nações Unidas sobre Assentamentos Humanos (Habitat II), em 1996, em Istambul, Turquia.

Com o conceito de desenvolvimento sustentável, construído a partir da Conferência das Nações Unidas sobre o Meio Ambiente Humano, em 1972, em Estocolmo, Suécia, inaugurado pelo Relatório “Nosso Futuro Comum", em 1987, e consolidado pela Rio-92, a Declaração de Istambul sobre Assentamentos Humanos, de 1996, foi além do direito à moradia adequada, prezando pela qualidade de vida de quem a habita, o que somente seria possível mediante um desenvolvimento sustentável.

De forma a sustentar nosso ambiente global e melhorar a qualidade de vida nos assentamentos humanos, nós nos comprometemos com padrões sustentáveis de produção, consumo, transporte e desenvolvimento de assentamentos; prevenção de poluição; respeito pela capacidade de absorção dos ecossistemas; e a preservação de oportunidades para gerações futuras (ONU, 1996).

Com a preocupação do desenvolvimento do entorno da moradia (ou da constatação de que as moradias devem ser construídas em áreas com infraestrutura urbana), um outro direito, ligado ao direito à moradia, foi ganhando força, até que em 2016, a Terceira Conferência das Nações Unidas sobre Moradia e Desenvolvimento Urbano Sustentável (Habitat III) consolidou o Direito à Cidade.

Considerando que o Brasil é signatário de diversos tratados e declarações internacionais que tratam sobre o direito à moradia, mas ainda possui um elevado déficit habitacional, esse trabalho tem por objetivo analisar a Segunda Conferência das Nações Unidas sobre Assentamentos Humanos (Habitat II), realizada em 1996, desde seu contexto histórico, até a Declaração de Istambul, documento final da 
Conferência, para, em um segundo artigo, que será oportunamente publicado, analisar a legislação federal brasileira pós Habitat II, verificando, assim, se o ordenamento jurídico brasileiro se adequou ao ordenamento jurídico internacional sobre o tema.

Para compreender a Declaração de Istambul, é necessário conhecer os fatores que influenciaram a Segunda Conferência das Nações Unidas sobre Assentamentos Humanos, por isso, estudaremos o contexto histórico desse evento. Serão, então, pesquisados trabalhos científicos que tratem do cenário internacional e nacional (brasileiro) em que a Conferência estava inserida. E, a partir dessa base bibliográfica, traçaremos a conjuntura histórica da Habitat II.

Posteriormente, analisaremos a Declaração de Istambul, documento final da Conferência, bem como documentos oficiais divulgados pela ONU durante os eventos preparatórios da Habitat II e documentos alternativos a que tivermos acesso, visto que os documentos da ONU não abordam todas as discussões envolvidas no evento. Com isso, será possível explicar o que foi a Habitat II, os principais pontos abordados durante as discussões e o conceito da ONU sobre moradia ao final da Conferência.

Porém, antes de estudar a Conferência Habitat II, seu contexto e seus desdobramentos na legislação brasileira, faz-se necessário entender o panorama brasileiro do direito à moradia, por isso, esse artigo se inicia com um estudo sobre o déficit habitacional no Brasil.

\section{O Brasil e o Direito à Moradia}

Signatário de todos os documentos internacionais supracitados, o Brasil trata o direito à moradia como um direito fundamental, inserto no artigo $6^{\circ}$ da Constituição Federal. Juntamente a transporte, educação, saúde, alimentação e outros, compõe o rol dos direitos sociais, ou seja, aqueles "decorrentes do princípio da igualdade não só formal, mas em especial, material, visando o alcance da igualdade stricto sensu" (KIM, 2015, p. 277) - segunda dimensão dos direitos humanos.

Nas palavras de Tavares (2012), direitos sociais são: “[direitos] que exigem do Poder Público uma atuação positiva, uma forma atuante de Estado na implementação da igualdade social dos hipossuficientes. São, por esse exato motivo, conhecidos também como direitos a prestação, ou direitos prestacionais" (TAVARES, 2012, p. 837).

A CF, portanto, determinou que é dever do Estado se comportar ativamente para garantir a seus cidadãos, em especial aos mais fracos e pobres (COMPARATO, 2010), uma situação de certeza, caracterizada pelo piso vital mínimo, o conjunto básico de direitos humanos, que efetivamente garante a dignidade da pessoa humana (FIORILLO, 2017).

Em que pese seja direito do cidadão ter acesso à moradia digna e dever do Estado agir para que esse direito se concretize, o déficit habitacional no Brasil supera a casa dos 5 milhões de domicílios, atingindo, em 2019, um déficit de 5.876.699 domicílios, segundo dados da Fundação João Pinheiro (FJP, 
2020). Para calcular esse número, a FJP adota um conceito amplo de déficit habitacional, levando em consideração "a falta de moradias e/ou a carência de algum tipo de item que a habitação deveria estar minimamente fornecendo e que, por algum motivo, não fornece" (FJP, 2020, p. 02).

Ou seja, se faltar algum elemento para que a moradia seja considerada digna, ela integra essa estatística. E como ressaltado no estudo da FJP: “o atual papel dos indicadores do déficit habitacional e da inadequação domiciliar é dimensionar a quantidade de moradias incapazes de atender o direito de acesso, por parte da população, a um conjunto de serviços habitacionais que sejam, pelo menos, básicos" (FJP, 2020, p. 03), conforme metodologia a seguir.

IMAGEM 1: Metodologia do déficit habitacional e da inadequação de domicílios no Brasil: 2016 - 2019. (FJP, 2020).

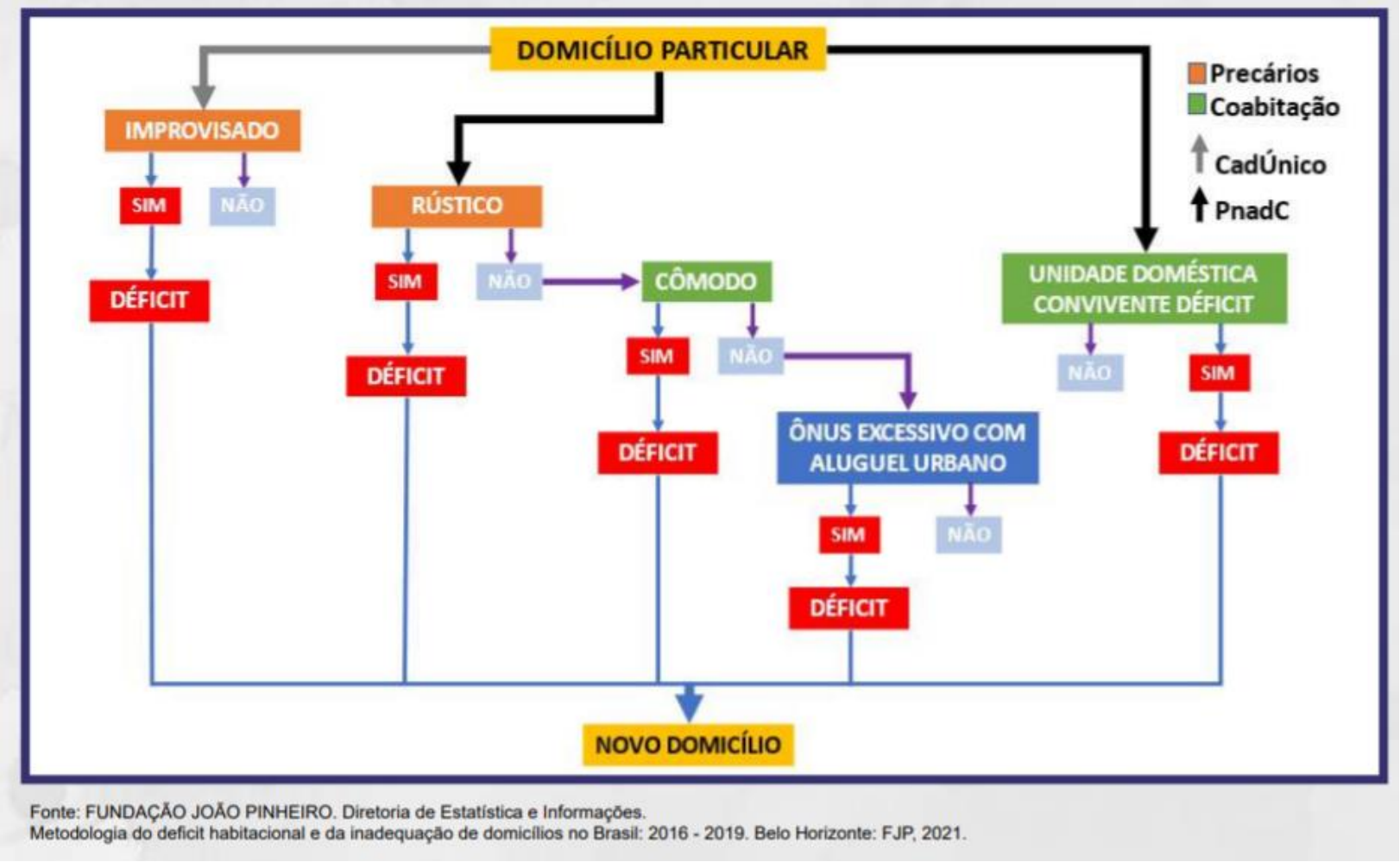

O déficit habitacional em sentido estrito considera as habitações precárias - domicílios rústicos ${ }^{6}$ ou improvisados ${ }^{7}$-, as coabitações - "domicílios com mais de 02 pessoas por cômodo servindo de dormitório" (FJP, 2020, p. 09) - e o ônus excessivo com aluguel urbano - considerando a renda domiciliar. Em 2019, foram identificadas 1.482 .585 habitações precárias e 1.358 .374 coabitações. O maior

\footnotetext{
6 “Aqueles sem paredes de alvenaria ou madeira aparelhada, o que resulta em desconforto e risco de contaminação por doenças, em decorrência das suas condições de insalubridade. Exemplos: taipas sem revestimento e madeira aproveitada." (FJP, 2020).

7 "Locais construídos sem fins residenciais e que servem como moradia. Exemplos: prédios em construção, viadutos, vagões de trem, carroças, tendas, barracas, grutas etc. que serviam de moradia na data de referência" (FJP, 2020).
} 
componente desse déficit, porém, é de aluguel excessivo, que, em 2019, correspondia a 51,7\% do índice (3.035.739 domicílios) (FJP, 2020).

Em sua análise histórica, o estudo demonstrou que, apesar da variação no déficit habitacional, de 2016 a 2019 o índice sempre se manteve acima dos 5,5 milhões de domicílios e, em todos os anos, o principal problema foi o ônus excessivo com aluguel urbano, conforme tabela a seguir.

TABELA 1: Déficit habitacional - componentes Brasil - 2016 a 2019

\begin{tabular}{|l|c|c|c|c|}
\hline \multirow{2}{*}{ Especificação } & \multicolumn{4}{|c|}{ Ano } \\
\cline { 2 - 5 } & 2016 & 2017 & 2018 & 2019 \\
\hline Habitação Precária & $\mathbf{1 . 2 9 6 . 7 5 4}$ & 1.490 .695 & $\mathbf{1 . 4 2 3 . 6 8 6}$ & $\mathbf{1 . 4 8 2 . 5 8 5}$ \\
Rústicos & 760.264 & 801.668 & 711.303 & 696.849 \\
Improvisados & 536.490 & 689.027 & 712.383 & 785.736 \\
Coabitação & $\mathbf{1 . 5 4 6 . 1 0 3}$ & 1.527 .259 & 1.400 .701 & $\mathbf{1 . 3 5 8 . 3 7 4}$ \\
Cômodos & 137.223 & 117.378 & 99.546 & 96.968 \\
Unidades Conviventes & 1.408 .880 & 1.409 .882 & 1.301 .155 & 1.261 .407 \\
Onus excessivo aluguel & $\mathbf{2 . 8 1 4 . 3 9 1}$ & $\mathbf{2 . 9 5 2 . 7 0 8}$ & $\mathbf{3 . 0 4 5 . 6 5 3}$ & $\mathbf{3 . 0 3 5 . 7 3 9}$ \\
urbano & & & & \\
& & & & \\
Déficit Habitacional & $\mathbf{5 . 6 5 7 . 2 4 9}$ & $\mathbf{5 . 9 7 0 . 6 6 3}$ & $\mathbf{5 . 8 7 0 . 0 4 1}$ & $\mathbf{5 . 8 7 6 . 6 9 9}$ \\
\hline \multicolumn{4}{|c}{} \\
\hline
\end{tabular}

Fonte: FJP, 2020

Porém, em que pese o aluguel urbano excessivo seja o principal problema, o número de habitações precárias é elevado, atingindo em 2019 quase 1,5 milhão de domicílios em todo país, sendo a situação mais crítica no Nordeste, com mais de $40 \%$ dessas habitações precárias, segundo o estudo da FJP.

TABELA 2: Distribuição percentual do total de Habitações precárias por regiões - Brasil - 2016 - 2019

\begin{tabular}{|c|c|c|c|c|}
\hline \multirow{2}{*}{ Regiões } & \multicolumn{4}{|c|}{ Habitações precárias (\%) } \\
\cline { 2 - 5 } & 2016 & 2017 & 2018 & 2019 \\
\hline Norte & 20,9 & 20,6 & 19,8 & 20,9 \\
\hline Nordeste & 45 & 41,4 & 43,1 & 42,8 \\
\hline Sudeste & 14,8 & 16,2 & 16,5 & 18,9 \\
\hline Sul & 11,9 & 14,5 & 13,7 & 10,8 \\
\hline Centro-Oeste & 7,5 & 7,3 & 6,8 & 6,6 \\
\hline Total & 100 & 100 & 100 & 100 \\
\hline
\end{tabular}

Fonte: FJP, 2020

A pesquisa mostrou, ainda, que as famílias com renda de até 2 salários mínimos são as que mais sofrem com a escassez de moradia, correspondendo a $42 \%$ dos afetados pelo déficit habitacional no país e a mais de $70 \%$ dos domicílios precários brasileiros, porcentagens que vão diminuindo de acordo com o aumento da renda familiar (Gráfico 1). 
GRÁFICO 1: Participação das faixas de renda nos componentes e no déficit habitacional do Brasil - 2019

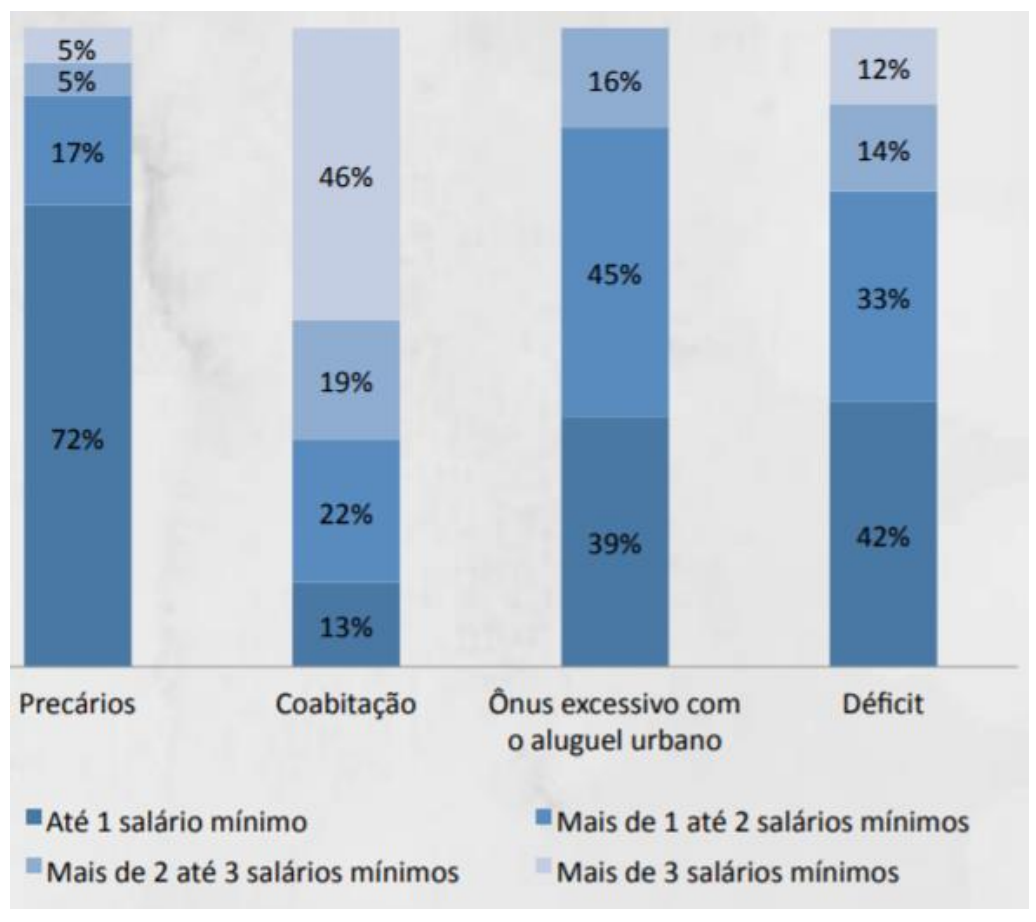

Fonte: FJP, 2020.

Já a inadequação domiciliar analisa: "Infraestrutura urbana (abastecimento de água, esgotamento sanitário, energia elétrica e coleta de lixo); carências edilícias (inexistência de banheiro exclusivo, número total de cômodos do domicilio igual a número de cômodos servindo de dormitório, armazenamento de água inadequado, piso inadequado, cobertura inadequada) e inadequação fundiária urbana" (FJP, 2020) de imóveis urbanos que não integram as estatísticas de déficit habitacional.

Segundo o estudo, os principais problemas que tornam o domicílio inadequado são o abastecimento de água, que entre 2016 e 2019 se manteve acima dos 10 milhões de habitações, e armazenamento inadequado de água, que em todos os referidos anos atingiu mais de 8 milhões de domicílios (FJP, 2020). 
TABELA 3: Domicílios urbanos duráveis segundo componentes da inadequação Brasil - 2016 a 2019

\begin{tabular}{|lcccc|}
\hline & \multicolumn{4}{c}{ Ano } \\
\cline { 2 - 5 } & 2016 & 2017 & 2018 & 2019 \\
\hline $\begin{array}{l}\text { Inadequações de } \\
\text { Infraestrutura Urbana }\end{array}$ & 13.920 .361 & 14.225 .490 & 13.683 .449 & 14.257 .395 \\
\hline Abastecimento de água & 10.535 .753 & 10.929 .414 & 10.293 .491 & 10.725 .833 \\
\hline Esgotamento Sanitário & 4.543 .831 & 4.551 .437 & 4.736 .936 & 4.916 .086 \\
\hline Energia elétrica & 400.407 & 419.290 & 456.109 & 406.143 \\
\hline Coleta de lixo & 801.730 & 690.316 & 640.265 & 553.350 \\
\hline Inadequações Edilícias & 10.301 .353 & 10.433 .213 & 10.777 .071 & 11.246 .366 \\
\hline Armazenamento & 8.283 .738 & 8.341 .592 & 8.624 .705 & 9.000 .021 \\
\hline Cômodos servindo de & 1.766 .699 & 1.757 .868 & 1.825 .851 & 1.886 .095 \\
\hline dormitório & 244.304 & 341.969 & 371.412 & 359.872 \\
\hline Ausência de banheiro & 862.832 & 1.058 .061 & 975.451 & 1.023 .757 \\
\hline Cobertura inadequada & 74.207 & 71.223 & 74.396 & 69.187 \\
\hline Piso inadequado & 2.514 .972 & 2.884 .350 & 2.996 .006 & 3.557 .117 \\
\hline Inadequação fundiária & & & & 24.893 .961 \\
\hline
\end{tabular}

Fonte: FJP, 2020.

E, assim como no déficit habitacional, a região mais atingida pela inadequação domiciliar é o nordeste, especialmente em relação a inadequações edilícias e de infraestrutura (FJP, 2020).

Uma análise histórica demonstra que o problema do déficit habitacional é antigo e já em 2007 ultrapassava a casa dos 5,8 milhões de domicílios, conforme demonstrado na tabela 4.

TABELA 4: Déficit Habitacional (FJP, 2015)

\begin{tabular}{|c|c|c|c|c|c|c|c|c|}
\hline $\begin{array}{c}\text { Região/ } \\
\text { Ano }\end{array}$ & $\mathbf{2 0 0 7}$ & $\mathbf{2 0 0 8}$ & $\mathbf{2 0 0 9}$ & $\mathbf{2 0 1 0}$ & $\mathbf{2 0 1 1}$ & $\mathbf{2 0 1 2}$ & $\mathbf{2 0 1 3}$ & $\mathbf{2 0 1 4}$ \\
\hline Norte & 614.583 & 559.951 & 645.226 & 823.442 & 613.188 & 564.620 & 652.998 & 632.067 \\
\hline Nordeste & 2.056 .826 & 1.919 .236 & 2.018 .797 & 2.111 .517 & 1.937 .074 & 1.777 .212 & 1.844 .141 & 1.900 .646 \\
\hline Sudeste & 2.156 .007 & 1.989 .754 & 2.173 .778 & 2.674 .428 & 1.984 .196 & 2.108 .602 & 2.246 .364 & 2.425 .679 \\
\hline Sul & 645.093 & 564.757 & 580.608 & 770.749 & 583.875 & 550.726 & 628.104 & 645.189 \\
\hline $\begin{array}{c}\text { Centro- } \\
\text { Oeste }\end{array}$ & 382.866 & 404.011 & 479.567 & 560.555 & 463.635 & 429.402 & 474.433 & 464.480 \\
\hline Brasil & 5.855 .375 & 5.437 .709 & 5.897 .976 & 6.940 .691 & 5.581 .968 & 5.430 .562 & 5.846 .040 & 6.068 .061 \\
\hline
\end{tabular}


Esse déficit habitacional histórico pode ser explicado pela política habitacional brasileira adotada desde a Lei de Terras, de 1850, que regulamentou a propriedade privada das terras brasileiras após a independência de Portugal. Como ressaltam Araújo e Fernandes (2010), as primeiras Constituições Brasileiras (1824 e 1891) privilegiaram o direito de propriedade privada plena, que somente veio a sofrer restrições com a introdução do princípio da função social da propriedade pela Constituição de 1934.

Não obstante a alteração a nível constitucional ter ocorrido somente no século XX, no final do século XIX, o governo começou a conceder "benefícios especiais às empresas e exigir que elas demolissem casas precárias e adotassem padrões de higiene, comodidade e maior dimensão para as moradias recémconstruídas" (ARAÚJO E FERNANDES, 2010, p. 126) - tradução nossa. E, em razão do receio de surgimento de novas pandemias, havia uma especial preocupação com o saneamento.

Já no início do século XX, a forte migração europeia rumo ao Brasil não só contribuiu para a intensificação da urbanização das cidades, como também para o fortalecimento de ideias socialistas, que culminaram, no início da década de 1940, na "intervenção sistemática do Estado brasileiro na produção e comercialização da moradia social" (ARAÚJO E FERNANDES, 2010, p. 129 ) - tradução nossa. Iniciou-se, assim, a política habitacional brasileira, que foi se aprimorando ao logo dos anos, até as políticas habitacionais adotadas no século XXI.

Apesar de esse trabalho ter por objetivo analisar a legislação federal brasileira a respeito do direito à moradia, não podemos desconsiderar a extrema gravidade social das moradias no Brasil, demonstrada pela pesquisa da FJP, bem como a urgente necessidade de elaboração de políticas públicas eficientes para combater esse déficit habitacional, em especial para as famílias com renda de até 2 salários mínimos.

Evidentemente a legislação brasileira atual não é suficiente para combater essa situação. É inegável, porém, que sem a legislação atual, tanto a nível nacional, quanto a nível internacional, a situação seria mais grave, por isso o estudo das 3 Conferências da ONU Habitat e o reflexo delas na legislação brasileira se faz necessário. A seguir, portanto, será estudada a Segunda Conferência das Nações Unidas sobre Assentamentos Humanos e, na segunda parte desse artigo, a legislação federal brasileira entre 1996 e 2016 (período entre a Habitat II e a Habitat III).

\section{HaBitat II: a Segunda Conferência das Nações Unidas sobre Assentamentos Humanos}

Em 1996 foi realizada em Istambul, na Turquia, a Conferência das Nações Unidas sobre Assentamentos Humanos, também conhecida como Habitat II. Diferentemente da primeira Conferência da ONU sobre o tema, a Habitat II foi um megaevento, que reuniu representantes governamentais, empresários, acadêmicos e a sociedade civil, dando sequência aos eventos da Década das Conferências 
(anos 90) e resultando em um novo documento com orientações a respeito dos temas moradia e assentamentos humanos.

\subsection{Contexto Histórico e eventos preparatórios}

A década de 1990 começou com o fim da Guerra Fria, após a queda do muro de Berlim, em 1989, e o fim da União Soviética, em 1991, e foi marcada por grandes Conferências de direitos humanos.

Logo após o término da Guerra, o Rio de Janeiro (Brasil), sediou a Conferência das Nações Unidas sobre Ambiente e Desenvolvimento, um dos mais importantes encontros planetários do século XX, que ficou conhecida com Eco-92, Rio-92 ou Cúpula da Terra. Reunindo mais de 45 mil pessoas de 175 países do mundo, a Conferência, realizada entre 03 e 14 de junho de 1992, "chamou a atenção do mundo para a dimensão global dos perigos que ameaçam a vida no Planeta e, por conseguinte, para a necessidade de uma aliança entre todos os povos em prol de uma sociedade sustentável” (BRASIL, 1995, p.7).

A magnitude do evento pode ser vista nos documentos gerados após esses 11 dias de discussão: Convenção sobre Mudança do Clima, Convenção sobre Biodiversidade, Declaração sobre Florestas, Declaração do Rio e Agenda 21.

A Declaração do Rio sobre Meio Ambiente e Desenvolvimento estabeleceu uma nova parceria global para a proteção do meio ambiente e promoção do desenvolvimento, apresentando 27 Princípios orientadores, sendo o Primeiro a respeito da centralidade dos seres humanos na preocupação dos países e organismos internacionais para promoção do desenvolvimento sustentável (ONU, 1992).

Apesar de a Declaração ressaltar a soberania dos países quanto à exploração de seus recursos, limitou essa exploração a não provocação de danos ao meio ambiente de outros Estados, bem como ao direito de as futuras gerações usufruírem dos recursos da Terra, sendo a proteção ambiental elemento essencial do desenvolvimento sustentável. Esse modelo de desenvolvimento, porém, engloba outros elementos, além da proteção ambiental, especialmente, a erradicação da pobreza (ONU, 1992).

O documento ressaltou, ainda, que seria necessária uma mudança cultural, com auxílio dos conhecimentos científicos e tecnológicos, para a promoção do desenvolvimento sustentável, mudando, principalmente, os padrões de produção e consumo insustentáveis que predominavam no Planeta. E, além de destacar a importância das legislações nacionais, a Declaração assegurou aos cidadãos o direito de participar das decisões acerca da proteção ambiental e o dever desses em auxiliar na promoção do desenvolvimento sustentável (ONU, 1992).

A Declaração, por fim, assegurou o direito dos oprimidos (jovens, mulheres, indígenas), inclusive o direito de plena participação na sociedade e igualdade de direitos em relação aos demais e asseverou 
que "a paz, o desenvolvimento e a proteção ambiental são interdependentes e indivisíveis" (ONU, 1992, p. 4).

Já a Agenda 21 elencou os desafios do século XXI, estabelecendo diretrizes a serem seguidas pelos países para enfrentá-los. Dessa forma, a Agenda 21 tratou de temas como: desenvolvimento sustentável dos assentamentos humanos, combate à pobreza, mudança dos padrões de produção e consumo, promoção da saúde humana, proteção da atmosfera, gerenciamento dos recursos terrestres, combate ao desflorestamento, o desenvolvimento rural e agrícola sustentáveis, conservação da biodiversidade, proteção dos recursos hídricos, manejo de resíduos, fortalecimento de mulheres e jovens, reconhecimento das populações indígenas e comunidades locais, além dos recursos para a implementação dessa Agenda (BRASIL, 1995).

Em relação ao desenvolvimento sustentável dos assentamentos humanos, a Agenda 21 apresentou as diretrizes a serem seguidas pelos países para a melhoria da qualidade (ambiental, social e econômica) dos assentamentos humanos, bem como das condições de vida e de trabalho das pessoas:

(a) Oferecer a todos habitação adequada;

(b) Aperfeiçoar o manejo dos assentamentos humanos;

(c) Promover o planejamento e o manejo sustentáveis do uso da terra;

(d) Promover a existência integrada de infraestrutura ambiental: água, saneamento, drenagem e manejo de resíduos sólidos;

(e) Promover sistemas sustentáveis de energia e transporte nos assentamentos humanos;

(f) Promover o planejamento e o manejo dos assentamentos humanos localizados em áreas sujeitas a desastres;

(g) Promover atividades sustentáveis na indústria da construção;

(h) Promover o desenvolvimento dos recursos humanos e da capacitação institucional e técnica para avanço dos assentamentos humanos (BRASIL, 1995, p. 72).

E, tratando o acesso à moradia adequada como essencial ao bem-estar físico, psicológico, social e econômico das pessoas, o documento definiu que o primeiro passo para alcançar esse objetivo seria a oferta de habitação para os sem-teto das camadas mais pobres da sociedade, bem como os desempregados e sem renda, por meio da facilitação do acesso à terra e programas habitacionais (BRASIL, 1995).

Para garantir a qualidade ambiental dos assentamentos humanos, a Agenda propôs a construção de casas ambientalmente adequadas e programas para enfrentamento do êxodo rural, que causa o crescimento desordenado das cidades e a concentração de pessoas, afetando negativamente o meio 
ambiente local. O Documento propôs, ainda, uma cooperação internacional para financiamento de moradias adequadas, em especial, nos países em desenvolvimento (BRASIL, 1995).

No ano seguinte, Viena (Áustria) recebeu, entre 14 e 25 de junho de 1993, a Conferência Mundial sobre Direitos Humanos, realizada com vistas a reforçar o empenho global na promoção e no respeito aos direitos humanos, principalmente saúde, alimentação e habitação (ONU, 1993).

Em 1994, realizou-se no Cairo (Egito) a Conferência Internacional sobre População e Desenvolvimento, reunindo mais de dez mil participantes, entre representantes governamentais e sociedade civil organizada. Dentre seus Princípios orientadores, incluiu o ser humano como o centro das questões do desenvolvimento sustentável, a quem é garantido o direito à qualidade de vida, por meio de "educação básica, saneamento, água potável, habitação, adequada oferta de alimento e infraestrutura para populações" (UNFPA, 1994, p. 47), devendo o Poder Público realizar políticas para garantir tais direitos.

Já em 1995, Copenhague (Dinamarca) sediou a Cúpula Mundial sobre Desenvolvimento Social, que reconheceu a "importância do desenvolvimento social e do bem-estar da humanidade" (ONU, 1995). Além de reafirmar os direitos a educação, alimentação, habitação, infraestrutura, emprego, saúde e informação, presentes em diversos tratados internacionais sobre direitos humanos, a Cúpula traçou como principal meta a erradicação da pobreza, garantindo a todos os direitos humanos, com atenção especial a mulheres e jovens. E assumiu o compromisso, dentre outros, de aumentar a disponibilidade de habitações adequadas e econômicas (ONU, 1995).

\subsection{A Conferência de Istambul}

Realizada entre 03 e 14 de junho de 1996, a II Conferência das Nações Unidas sobre Assentamentos Humanos reuniu os países integrantes da ONU para "endossar as metas universais para garantir moradia adequada a todos e tornar os assentamentos humanos mais seguros, saudáveis, habitáveis, equitativos, sustentáveis e produtivos" (ONU, 1996).

Ao final das discussões, foi redigida a Declaração de Istambul, bem mais enxuta do que a Declaração de Estocolmo, pois não apresentou um plano de ações, porém com muitas metas traçadas.

O documento começa afirmando que a Conferência focou em dois grandes temas: 'Moradia Adequada para Todos' e 'Desenvolvimento de Assentamentos Humanos Sustentáveis em um Mundo em Processo de Urbanização'. A inabitabilidade de boa parte dos assentamentos humanos, que havia sido destacada na Habitat I, permaneceu em destaque aqui em razão da deterioração que as habitações estavam sofrendo, tornando urgente o enfrentamento a essa questão. $E$ a solidariedade entre os povos continuou sendo proposto pela ONU como um pilar para encarar adversidades (ONU, 1996). 
A década de 1990 foi marcada por diversas Conferências da ONU, conforme já ressaltado, em especial a Conferência das Nações Unidas para o Meio Ambiente e o Desenvolvimento (ECO-92), que consolidou a busca por um desenvolvimento sustentável. E, reforçando essa nova proposta de desenvolvimento, a Declaração de Istambul ressaltou a necessidade de mudança nos padrões de produção e consumo, distribuição populacional e desenvolvimento humano, para permitir a melhoria na qualidade de vida das populações (ONU, 1996).

Ainda em relação à preocupação ambiental, a Declaração reconheceu a necessidade de se adotar o Princípio da Precaução no desenvolvimento dos assentamentos humanos para promover ambientes de vida saudáveis (ONU, 1996).

A ONU reconheceu, então, a desigualdade que marca a divisão dos países desenvolvidos e em desenvolvimento e a necessidade de colaborar com o desenvolvimento desses últimos, por meio de financiamentos, pois somente assim seria possível promover um avanço na busca por moradias adequadas e assentamentos humanos sustentáveis (ONU, 1996).

Apesar de a Habitat II preocupar-se predominantemente com o desenvolvimento urbano, em razão da rápida urbanização e de quase $75 \%$ da população dos países desenvolvidos residirem em áreas urbanas (ONU, 2014), aproximadamente $55 \%$ da população mundial ainda vivia em áreas rurais (ONU, 2014). Portanto, um dos itens da Declaração de Istambul dedicou-se ao desenvolvimento das áreas rurais, frisando a imprescindibilidade de "estender a infraestrutura adequada, serviços públicos e oportunidades de emprego" (ONU, 1996) para essas áreas.

E, assim como na Habitat I, os seres humanos foram colocados como foco central das preocupações, visto que a busca por uma moradia adequada se baseia na qualidade de vida desses. E a necessidade de inclusão de mulheres, jovens e crianças na vida social, política e econômica foi destacada, bem como a de proteção a esses grupos, que deveriam ser tratados em igualdade com os demais (ONU, 1996).

O documento salientou, ainda, que mais de um bilhão de pessoas viviam em situação de pobreza extrema e que todos os esforços seriam imprimidos para combater essa situação, de forma a buscar um desenvolvimento sustentável dos assentamentos humanos (ONU, 1996).

Considerando que a promoção de moradias adequadas tem um custo, a ONU propôs parcerias entre entes públicos, privados e não governamentais para permitir o acesso de todos a moradias adequadas e a preços acessíveis, sem suprimir, no entanto, as responsabilidades social e ambiental, que completam o tripé da sustentabilidade. Bem como a união internacional de esforços para "facilitar a capacitação e promover a transferência de tecnologias e conhecimentos apropriados" (ONU, 1996). 
Por fim, a Declaração de Istambul deixou uma mensagem positiva e esperançosa, para que os países alcançassem as metas propostas na Conferência e as pessoas tivessem qualidade de vida e seus direitos respeitados:

Esta conferência em Istambul marca uma nova era de cooperação, uma era da cultura da solidariedade. À medida que entramos no século XXI, nós oferecemos uma visão positiva dos assentamentos humanos sustentáveis, um senso de esperança para o nosso futuro comum e um estímulo para enfrentarmos um desafio verdadeiramente válido e comprometedor, o de construirmos juntos um mundo onde todos possam viver em uma casa segura, com a promessa de uma vida decente, com dignidade, boa saúde, segurança, felicidade e esperança (ONU, 1996).

A Habitat II, portanto, teve como foco principal a busca pelo desenvolvimento sustentável dos assentamentos humanos: i) sustentabilidade social, por meio da erradicação da pobreza, da inclusão de mulheres e jovens na vida econômica, social e política e redução das desigualdades locais e regionais; ii) sustentabilidade ambiental, por meio do respeito ao meio ambiente, do cumprimento ao disposto na Agenda 21 e mudanças nos padrões de produção e consumo; ii) sustentabilidade econômica, por meio da redução dos custos das moradias adequadas e transferência de tecnologia para os países em desenvolvimento. Além disso, classificou o direito à moradia como um direito humano e universal, mesmo que essa classificação não resultasse na imediata internalização desse direito por todos os países.

\section{CONCLUSÕES PARCIAIS}

O déficit habitacional é um problema que atinge boa parte da população brasileira, especialmente a população com renda de até 2 salários mínimos e a população que vive no Nordeste do Brasil. Esse déficit não significa ausência de moradia, entendida como estrutura física, mas ausência de moradia digna, considerando os requisitos básicos.

A pesquisa da FJP demonstrou que esse problema é antigo e que por mais que os números variem, a média vem se mantendo há anos, o que demonstra a necessidade de rever a política habitacional brasileira. E essa revisão pode ser feita com base nos instrumentos internacionais, principalmente nos resultantes das Conferências ONU/HABITAT.

A Habitat II, estudada nesse artigo, teve um foco maior na sustentabilidade dos assentamentos humanos, visto que 4 anos antes havia se realizado no Rio de Janeiro a ECO-92. Sempre buscando um equilíbrio entre as dimensões econômica, social e ambiental do desenvolvimento, a Conferência tratou dos diversos direitos sociais relacionados a assentamentos humanos, tanto urbanos quanto rurais.

Na segunda parte deste artigo, a ser oportunamente publicada, analisaremos a legislação federal brasileira entre 1996 e 2016, ou seja, entre a Habitat II (Istambul, 1996) e a Habitat III (Quito, 2016), para 
verificarmos as influências diretas e indiretas da Declaração de Istambul no ordenamento pátrio sobre direito à moradia.

\section{REFERÊNCIAS}

Heloísa Oliveira de ARAÚJO y Rosali Braga FERNANDES. Derecho a la vivienda y a la ciudad Las políticas de la vivienda en Brasil. Cuadernos Electrónicos № 6. 2010. Disponível em: <

https://pradpi.es/cuadernos/6/5_-Heloisa-Oliveira-de-Araujo-Brasil.pdf>. Acesso em 22 ago. 2021.

ARZABE, Patrícia Helena Massa; GRACIANO, Potyguara Gildoassu. A Declaração Universal Dos Direitos Humanos - 50 anos. Disponível em: <

http://www.pge.sp.gov.br/centrodeestudos/bibliotecavirtual/direitos/tratado4.htm>. Acesso em 21 ago. 2017.

BRASIL. Conferência das Nações Unidas sobre o Meio Ambiente e Desenvolvimento (1995). Câmara dos Deputados. Disponível em: <http://www.onu.org.br/rio20/img/2012/01/agenda21.pdf>. Acesso em 05 jan. 2017.

. Constituição (1988). Constituição da República Federativa do Brasil. Brasília, DF: Senado Federal: Centro Gráfico, 1988 (e). 292 p.

CDESC. Comentário Geral n. 4: Artigo 11, número 1 (Relativo ao direito a alojamento adequado). 1991. Disponível em: < http://unhrt.pdhj.tl/por/artigo-11-o-numero-1-relativo-ao-direito-ao-alojamentoadequado/>. Acesso em: 19 mar. 2017.

CDESC. Comentário Geral n. 7: Artigo 11, número 1 (O direito a um alojamento adequado: desalojamentos forçados). 1997. Disponível em: <http://unhrt.pdhj.tl/por/artigo-11-o-numero-1-odireito-a-um-alojamento-adequado-desalojamentos-forcados/>. Acesso em: 19 mar. 2017.

COMPARATO, Fábio Konder. A Afirmação Histórica dos Direitos Humanos. 7ạ ed. Rev. E atual. - São Paulo: Saraiva, 2010.

FIORILLO, Celso Pacheco. O Processo De Afirmação Dos Direitos Humanos Em Face Do Conceito Constitucional De Direito Ambiental. Revista de Direito Brasileira. São Paulo, SP. v. 17. n. 7. p. 191 - 202. Mai./Ago. 2017.

FUNDAÇÃO JOÃO PINHEIRO. Déficit habitacional no Brasil. Belo Horizonte, 2015. Disponível em: < http://www.fjp.mg.gov.br/index.php/produtos-e-servicos1/2742-deficit-habitacional-no-brasil-3>. Acesso em 17 abr. 2018.

FUNDAÇÃO JOÃO PINHEIRO. Deficit Habitacional e Inadequação de Moradias no Brasil: Principais resultados para o período de 2016 a 2019. Belo Horizonte, 2020. Disponível em: < http://novosite.fjp.mg.gov.br/wp-content/uploads/2020/12/04.03_Cartilha_DH_compressed.pdf>. Acesso em 08 ago. 2021. 
KIM, Richard Pae. Separação de poderes e as teorias interna e externa dos direitos fundamentais: direitos sociais e a inaplicabilidade da teoria externa. Revista de Direito Brasileira. São Paulo, SP. ano 5. v. 10. p. $273-301.2015$.

MARICATO, Ermínia. Direito à moradia é absoluto na Constituição, o à propriedade não. Revista Brasileiros. Disponível em: < http://brasileiros.com.br/2017/01/direito-a-moradia-e-absoluto-o-apropriedade-nao-erminia-maricato/>. Acesso em 26 jan. 2017.

MAUAD, Ana Carolina Evangelista. A participação dos governos locais na Segunda Conferência das Nações Unidas sobre Assentamentos Humanos (Habitat II) e seus desdobramentos internacionais e nacionais. 2011, 140f. Dissertação (Mestrado em Relações Internacionais) - Universidade de Brasília, Brasília, 2011.

MENDES, Gilmar. Supremo Tribunal Federal. Voto no Recurso Extraordinário 466.343-1/SP. Relator: PELUSO, Cezar. Recorrente: Banco Bradesco AS. Recorrido: Luciano Cardoso dos Santos. Publicado no DJ de 05.06.2009. Disponível em: <http://www.stf.jus.br/imprensa/pdf/re466343.pdf>. Acesso em: 10 jun. 2017.

ONU. Comité dos Direitos Económicos, Sociais e Culturais - Comentários Gerais. Disponível em: < https://unhrt.pdhj.tl/por/pacto-internacional-sobre-os-direitos-economicos-sociais-e-culturais-pidesc/>. Acesso em: 19 mar. 2017.

em: . Conferência Mundial sobre Direitos Humanos. 1993. Organization of American States. Disponível <https://www.oas.org/dil/port/1993\%20Declara\%C3\%A7\%C3\%A3o\%20e\%20Programa\%20de\%20Ac\%C 3\%A7\%C3\%A3०\%20adoptado\%20pela\%20Confer\%C3\%AAncia\%20Mundial\%20de\%20Viena\%20sobre\%2 0Direitos\%20Humanos\%20em\%20junho\%20de\%201993.pdf>. Acesso em: 06 jan. 2017.

. Declaração de Istambul sobre Assentamentos Humanos. 1996. Disponível em:

<http://pfdc.pgr.mpf.mp.br/atuacao-e-conteudos-de-apoio/legislacao/moradiaadequada/declaracoes/declaracao-de-istambul-sobre-assentamentos-humanos $>$. Acesso em: 15 nov. 2017.

. Declaração do Rio sobre Meio Ambiente e Desenvolvimento. 1992. Disponível em: < http://www.onu.org.br/rio20/img/2012/01/rio92.pdf>. Acesso em: 05 jan. 2017.

. Declaração e Programa de Ação da Cúpula Mundial sobre Desenvolvimento Social -Copenhague. 1995. Universidade de São Paulo. Disponível em: <http://www.direitoshumanos.usp.br/index.php/Confer\%C3\%AAncias-de-C\%C3\%BApula-das$\mathrm{Na} \% \mathrm{C3} \% \mathrm{A7 \% C3 \% B5es-Unidas-sobre-Direitos-Humanos/declaracao-e-programa-de-acao-da-cupula-}$ mundial-sobre-desenvolvimento-social.html>. Acesso em: 06 jan. 2017.

. Declaração Universal dos Direitos Humanos. 1948. Disponível em: <http://www.onu.org.br/img/2014/09/DUDH.pdf>. Acesso em: 15 nov. 2017.

. Department of Economic and Social Affairs, Population Division. 2014. World Urbanization Prospects: The 2014 Revision, CD-ROM Edition. Disponível em: < https://esa.un.org/unpd/wup/CDROM/>. Acesso em: 20 ago. 2017.

. Pacto Internacional Sobre os Direitos Económicos, Sociais e Culturais. 1966. United Nations Human Rights Treaties. Disponível em: <http://unhrt.pdhj.tl/por/pacto-internacional-sobre-os-direitoseconomicos-sociais-e-culturais-pidesc/>. Acesso em: 15 nov. 2017. 
The Vancouver Declaration on Human Settlements. 1976. Disponível em:

<https://nacoesunidas.org/conheca-os-novos-17-objetivos-de-desenvolvimento-sustentavel-da-onu/>. Acesso em 15 nov. 2017.

RAMANZINI, Isabela Gerbelli Garbin. Supremo Tribunal Federal: equilíbrio entre a Constituição e os Tratados Internacionais. Boletim Meridiano. 47. vol. 15. n. 141. jan.-fev. 2014. p. 44 a 50.

RUBARTH, Ernesto Otto. A Diplomacia Brasileira e os Temas Sociais: o caso da saúde. Brasília. Instituto Rio Branco; Fundação Alexandre de Gusmão; Centro de Estudos Estratégicos, 1990.

TAVARES, André Ramos. Curso de Direito Constitucional. 10ạ ed. rev. e atual. - São Paulo: Saraiva, 2012.

UNFPA. Relatório da Conferência Internacional sobre População e Desenvolvimento. (1994). Disponível em: <http://www.unfpa.org.br/Arquivos/relatorio-cairo.pdf>. Acesso em: 08 jan. 2017. 